\title{
Incidence and biomarkers of pregnancy, spontaneous abortion, and neonatal loss during an environmental stressor: implications for female reproductive suppression in the cooperatively breeding meerkat
}

\author{
Kristin A. Dimac-Stohl ${ }^{\mathrm{a}, 1}$, Charli S. Davies ${ }^{\mathrm{a}, \mathrm{b}, 1,2}$, Nicholas M. Grebe ${ }^{\mathrm{a}, 1}$, Alexandra C. Stonehill ${ }^{\mathrm{a}}$, \\ Lydia K. Greene $\mathrm{a}^{\mathrm{a}, \mathrm{b}, \mathrm{c}}$, Jessica Mitchell ${ }^{\mathrm{a}, \mathrm{b}}$, Tim Clutton-Brock ${ }^{\mathrm{b}, \mathrm{d}, \mathrm{e}}$, \& Christine M. Drea $\mathrm{a}^{\mathrm{a}, \mathrm{b}, \mathrm{c}, \mathrm{f}, *}$ \\ ${ }^{a}$ Department of Evolutionary Anthropology, Duke University, 130 Science Drive, Durham, NC 27708, USA \\ ${ }^{\mathrm{b}}$ Kalahari Research Trust, Kuruman River Reserve, Northern Cape, South Africa \\ c University Program in Ecology, Duke University, Durham, NC 27708, USA \\ ${ }^{\mathrm{d}}$ Mammal Research Institute, University of Pretoria, Pretoria, South Africa \\ ${ }^{\text {e }}$ Department of Zoology, University of Cambridge, Cambridge, UK \\ ${ }_{\mathrm{f}}^{\mathrm{f}}$ Department of Biology, Duke University, Durham, NC 27708, USA \\ * Corresponding author. E-mail address: cdrea@duke.edu (C.M. Drea). \\ ${ }^{1}$ Co-first authors. \\ ${ }^{2}$ Present address: School of Biological Sciences, University of East Anglia, Norwich Research Park, Norwich, \\ Norfolk, NR4 7TJ, UK
}

\section{Highlights}

- Arid conditions related more to increased neonatal loss than spontaneous abortion.

- Climate change may reduce reproductive skew in the cooperatively breeding meerkat.

- Androgens more so than estrogens may mediate reproductive suppression in meerkats.

- Meerkat susceptibility to environmental vs. social stressors differs by status.

- Deciphering the mechanisms of cooperation requires long-term, integrated study. 


\section{ABSTRACT}

Meerkats are group-living, insectivorous herpestids in which subordinate members provide extensive care for the dominant female's young. In contrast to some cooperative breeders, subordinate female meerkats are physiologically able to reproduce and occasionally do so successfully; their attempts are more frequently 'suppressed' via eviction or infanticide by the dominant female. Spontaneous abortion and neonatal loss occur with some regularity, further negatively impacting reproductive success. Here, we compared the reproductive outcomes and endocrine profiles, including of serum progesterone $\left(\mathrm{P}_{4}\right)$, serum estradiol $\left(\mathrm{E}_{2}\right)$, and fecal glucocorticoid metabolites (fGCm), of dominant and subordinate dams residing within their clans in the Kalahari Desert of South Africa. Our study spanned years of drought, which reduced insect abundance and represented a substantial environmental stressor. Meerkat pregnancies were identified at mid-term and culminated either in spontaneous abortions or full-term deliveries, after which pups were either lost prior to emergence from the natal den (usually within 2 days of birth) or emerged at 2-3 weeks. Neonatal loss exceeded fetal loss for all females, and contributed to narrowing the status-related disparity in female reproductive output seen during less arid periods. Although $\mathrm{E}_{2}$ concentrations were significantly lower in subordinate than dominant females, they were sufficient to support gestation. Absolute $\mathrm{E}_{2}$ concentrations may owe to androgenic precursors that also attain highest concentrations in dominant dams and may mediate aggression underlying female reproductive skew. Pregnancies terminating in fetal loss were marked by significantly lower $\mathrm{P}_{4}$ concentrations in mid-gestation and modestly lower $\mathrm{E}_{2}$ concentrations overall. Consistently high fGCm concentrations further increased across trimesters, particularly (but not consistently) in subordinates and in aborted pregnancies. Environmental stressors may modulate reproductive outcomes in meerkats through their 
influence on sex steroids and their effects on intragroup competition. The social and ecophysiological factors affecting intraspecific variation in reproductive output, even in obligate cooperative breeders, may be most apparent during extreme conditions, reflecting the benefits of long-term studies for assessing the impact of climate change.

\section{Keywords}

Cooperative breeding; Social dominance; Reproductive and stress hormones; Fetal and neonatal mortality; Reproductive success; Climate change

\section{Introduction}

\subsection{The biopsychosocial model of fetal loss}

Fetal loss negatively impacts mammalian reproductive success; yet, owing to difficulties of study, we know remarkably little about the incidence of and circumstances surrounding spontaneous abortion in mammals, particularly in the wild. One of the major hypotheses advanced to explain adverse pregnancy outcome beyond the selective elimination of genetically unfit embryos [1,2], involves prenatal maternal stress (i.e., the biopsychosocial model; reviewed in [3]). Studies of the stress-related etiology of fetal loss fall into four broad categories: (1) The most common are clinical studies of human populations, which are focused on the network of physiological processes [4] and psychosocial predictors [5-7] associated with pregnancy maintenance versus reproductive failure, with goals of prevention or intervention to minimize recurrent miscarriages. (2) Experimental laboratory studies (mostly of rodent, rabbit or nonhuman primate models) [8-11] generally share the goals of human studies. (3) In studies of farm animals (primarily ungulates), researchers investigate the predictors of fetal wastage with 
the aim of minimizing economic losses [12-14]. (4) Least common are studies of zoo animals [15] or wild populations (mostly of primates), in which researchers examine natural variation in fetal loss with the aim of understanding the evolutionary (and conservation) implications of social, demographic, and ecological factors associated with fetal loss [hares: 16; ungulates: 17; primates: 18-22], many of them using recently developed noninvasive techniques to evaluate endocrine biomarkers $[23,24]$. Our study falls within this last category, but, uniquely, is focused on a social carnivoran and obligate cooperative breeder, the meerkat (Suricata suricatta). We examine reproductive outcomes in the wild, in both dominant and subordinate dams, and use various endocrine biomarkers to assess the role of fetal or neonatal loss in the reproductive suppression of subordinate females.

\subsection{The cooperatively breeding meerkat}

Meerkats are small-bodied, social mongooses that live in harsh environments in territorial groups or clans of up to 50 individuals $[25,26]$. They are considered to be singular cooperative breeders, with one dominant female per group breeding most regularly [27-29]. Subordinates are usually offspring or siblings of the dominant pair and (with the exception of lactation) provide the majority of infant care. Subordinate females contribute to suckling the offspring of dominant females [30], and helpers of both sexes guard, carry, provision, and protect juveniles born in their group [25,27], thereby investing significant energetic resources in raising the offspring of others. As in many other singular cooperative breeders [31-34], subordinate meerkats occasionally attempt to breed and sometimes rear young successfully [28].

Relative to other cooperatively breeding mammals like mole rats [35,36], callitrichid primates [37], and canids [38-40], meerkats suffer significant predation pressure [41] and are 
exceptional in the extent of their cooperative activities [42]. Their pronounced need for babysitters $[43,44]$ and sentinels [45] may increase the evolutionary pressures for phenotypic divergence between breeders and helpers [46,47] - phenotypic divergence that is likely to be underwritten, in part, by endocrine mechanisms. Whereas the ultimate evolutionary drivers of cooperative systems have been studied extensively, much less attention has been accorded the proximate physiological mechanisms underpinning extreme 'reproductive skew' or the unequal distribution of reproductive output (see also $[48,49]$ ).

\subsection{Fetal loss as a mechanism of reproductive suppression}

Across cooperatively breeding species, various mechanisms account for the stress-related, reproductive suppression of subordinate females, whereby higher glucocorticoid concentrations, arising as a consequence of the stress of subordination, interfere with reproductive function (for a review, see [48]). These mechanisms of reproductive suppression include five major categories: delayed puberty, inhibition of ovulation, implantation failure, spontaneous abortion, and infant mortality [50]. The neuroendocrine impairment of reproductive function evident in certain species [51-53] is not as readily apparent in female meerkats because, despite status-related differences in basal concentrations of estrogen [54-56] and luteinizing hormone [57], all adult female meerkats are physiologically able to reproduce [57]. Nevertheless, subordinates produce roughly one third the number of litters as that produced by dominant females [27]. Perhaps instead of physiological suppression, significant reproductive skew in meerkats owes primarily to behavioral tactics by the dominant female, including the eviction of pregnant subordinates, which often precipitates fetal loss, and the killing or group abandonment of their pups [57,58]. 


\subsection{The biopsychosocial model in meerkats}

The role of social stress in contributing to reproductive skew among female meerkats remains equivocal. Examining status-related differences in glucocorticoids (GCs), Carlson and colleagues [54] found that dominant animals were more likely than subordinates to have measurable plasma GCs. Although Barrette and colleagues [59] found no status-related differences in fecal GCs, they reasoned that dominant females would endure the greatest cumulative stress because GCs increase with pregnancy and dominant females reproduce most frequently. A prolific dominant female can conceive again just nine days after parturition and can bear up to four litters per year [59,60]. Although Young and colleagues [56] also found no status-related differences in fecal GCs within female clan members, they [60] found that subordinate females evicted from the clan suffered significantly greater, stress-related fetal loss than did their subordinate counterparts residing within the clan.

Related to these findings, Clutton-Brock and colleagues [61] reported abortion rates within the clan to be significantly greater in subordinate than in dominant females. Although subordinates residing within the clan are no more likely to abort their litters if the dominant female is pregnant than if she is not pregnant [62], they express greater plasma GC concentrations while the dominant female is pregnant than they do at other times [63]. Lacking from studies of social stress in meerkats, however, is a concurrent examination of reproductive hormones and a comparison of the endocrine correlates of abortion between classes of animals residing within the clan. 


\subsection{Aim of the present study}

Previous researchers have identified various maternal factors predicting fetal loss, including species, age, rank, reproductive history, parity, weight, nutritional state, histocompatibility, litter size, and even fetal uterine position [64-68]. Our first aim was to examine maternal factors (particularly female social dominance, while controlling for weight) relative to fetal and neonatal loss, and to test if steroid hormone concentrations during and immediately after gestation might be associated with reproductive outcome in each of the social classes. We thus examined various endocrine biomarkers in dominant and subordinate females during term pregnancies and during spontaneous abortions, as well as during their respective post-pregnancy periods.

Across species, significant environmental factors, including temperature, rainfall or season, and population density or group size, also have been identified in fetal loss $[18,61,68]$. In the course of monitoring pregnancies in this wild population of meerkats, a drought that spanned several years represented an environmental stressor that may have influenced pregnancy outcomes in one or both of the social classes. Notably, insects constitute the meerkat's primary prey class, and their diversity and abundance fluctuate with temperature and rainfall [69]. Because foraging effort is greatest in pregnant and lactating females [69], these animals could be particularly vulnerable to low prey availability, particularly in larger groups. Thus, our second, integrated aim was to examine pregnancy outcomes and maternal reproductive and stress physiology during a time of substantial environmental stress (namely, a period of lower rainfall relative to earlier study periods). We asked if resident, subordinate dams might be even more prone than dominant dams to abort or if the drought leveled the reproductive 'playing field.' Evidence of the latter could be relevant to understanding environmental influences that 
contribute to intraspecific flexibility [49], in this case between singular and plural cooperative breeding.

\subsection{Choice of endocrine biomarkers}

We focused our investigation on serum progesterone $\left(\mathrm{P}_{4}\right)$, serum estradiol $\left(\mathrm{E}_{2}\right)$, and, as a proxy for circulating GCs, fecal glucocorticoid metabolites (fGCm), because these steroids play pivotal roles in the establishment and maintenance of pregnancy, in the regulation of fetalplacental development, in fetal programming, and/or in parturition and early lactation [70-74]. These steroids are also known correlates of spontaneous abortion [6,75]. Moreover, because of endocrine-immune interactions, evidenced by the role of $\mathrm{P}_{4}$ in immuno-modulation of maternal tolerance of the fetus, there is evidence that stress can diminish $\mathrm{P}_{4}$ concentrations and lead to premature pregnancy termination (reviewed in [76]) or reduced offspring recruitment [17]. Indeed, changes in serum concentrations of cortisol can both increase the clearance rate and decrease the production rate of $\mathrm{P}_{4}$ [77]. In sum, there are complex interrelationships among concentrations of these hormones and maternal factors, the environment, various stressors, and prenatal survival [68] that may be relevant to explaining reproductive suppression in the meerkat.

\section{Methods}

\subsection{Study site}

We conducted our study between November 2011 and March 2015 on a wild, but habituated, population of meerkats living in the Kuruman River Reserve (KRR), in the Kalahari Desert of

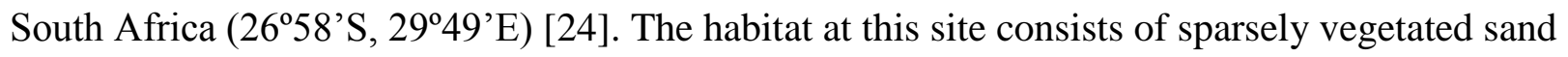
dunes and herbaceous flats [41]. The mean annual rainfall, calculated over 20 early years, was 
$217 \mathrm{~mm}$ [41] and, more recently, in the two years preceding our study, was 446-467 $\mathrm{mm}$. By contrast, during the span of our study, the KRR experienced a prolonged drought, such that annual rainfall was $144-193 \mathrm{~mm}$.

\subsection{Subjects and their pregnancies}

Meerkat population and clan numbers at the KRR fluctuate dramatically, owing to pup turnover (i.e., births and deaths), adult immigration from and emigration to the surrounding area, the formation, disbanding or demise of clans (e.g. as a result of disease outbreaks), and changes in group ranging patterns [78]. During our study period, there was an annual average of roughly 270 individuals from 22 clans and a total of roughly 810 animals from 43 clans. Our focal subjects included 75 unique, adult females, deriving from 22 clans (that ranged in size from 4-36 animals). All of the animals were individually identifiable via unique dye marks and were habituated to close observation $(<1 \mathrm{~m})$ and routine weighing (i.e., up to three times per observation day and for which animals were trained to climb onto an electronic balance) [25]. Thus, we knew the social status of each animal and could collect detailed life-history and weight data, as well as serum or fecal samples for endocrine assay (see below).

Each of our focal females experienced one or more pregnancies during the 41-month period of study (see below). Twelve of these females changed social status during the course of the study and became pregnant at least once while occupying each status, such that our analyses ultimately involved 87 representatives of the two classes: 37 dominant dams (aged 9 mo $-9.5 \mathrm{yr}$ ) and 50 subordinate dams (aged $7 \mathrm{mo}-5.1 \mathrm{yr}$ ). As can be seen by the lower limits of these age ranges, our data set included dams that were several months younger than is typically the case (i.e., sexual maturity generally occurs around 1 year of age [61]). 
Based on the conservative selection criteria detailed below, we monitored 141 pregnancies (or breeding attempts) that were roughly equally distributed by female social status: 67 (47.5\%) of these events involved dominant females and 74 (52.5\%) involved subordinate females (see Table 1). The vast majority of these pregnancies occurred while the females resided within their clans (i.e., only twice were any of the focal females evicted before the end of their pregnancies); all of the hormone data we present reflect samples collected during the female's residency within the clan.

Table 1. Number (and percentages) of breeding attempts and their outcomes by female social status in the cooperatively breeding meerkat, across a 41-month period of study.

\begin{tabular}{|c|c|c|c|c|c|c|c|}
\hline \multirow[t]{2}{*}{ Female status } & \multirow{2}{*}{$\begin{array}{l}\text { Breeding } \\
\text { attempts }\end{array}$} & \multicolumn{2}{|c|}{ Abortions (A) } & \multicolumn{4}{|c|}{ Term births ( $\mathrm{T})$} \\
\hline & & Mid-term & Late-term & Total $_{A}$ & Loss & Emergence & Total \\
\hline Dominant & $67(47.5 \%)$ & $6(75 \%)$ & $8(28.6 \%)$ & $14(38.9 \%)$ & $15(41.7 \%)$ & $38(55.1 \%)$ & $53(50.5 \%)$ \\
\hline Subordinate & $74(52.5 \%)$ & $2 *(25 \%)$ & $20(71.4 \%)$ & $22(61.1 \%)$ & $21(58.3 \%)$ & $31(44.9 \%)$ & $52(49.5 \%)$ \\
\hline Total & 141 & 8 & 28 & 36 & 36 & 69 & 105 \\
\hline
\end{tabular}

* An observed abortion occurred on the cusp between early- and mid-gestation.

\subsection{Monitoring pregnancies and their outcomes}

To monitor pregnancies and their outcomes, meerkat groups were visited and all adult females were observed every 1-3 days. Pregnancy is usually detectable by an increase in the dam's weight and/or by visible (and palpable) swelling of her abdomen [79] around the midpoint of her 70-day gestation period [58]. Likewise, abortions are usually detectable by early weight loss, accompanied by a return to normal abdomen size and shape, and sometimes by signs of blood. Additionally, during our routine observations of animals above ground, we witnessed nearly a third (11/36 or $31 \%)$ of the abortions reported herein. Meerkats generally bear litters of 
three to six pups (mean $=4.1$ ) and although fetal reabsorption (i.e., litter reduction) is possible, ultrasound scanning has shown consistency of prenatal litter size over time [80]. The abortions on which we report involved loss of the entire litter.

We also detected parturition by the dam's shape change and sudden weight loss (Figure 1), as well as by the presence of babysitters [27], and we confirmed live births by suckle marks around the dam's nipples [79]. After parturition, pups remain within the underground burrow system for roughly their first two-three weeks of life [30]. We therefore defined the early post-partum or post-abortion (hereafter 'post-pregnancy') period as the first 20 days after delivery or spontaneous abortion. Because pre-emergence losses occur underground, their causes are not ascertained, but could include stillbirth, predation, infanticide or abandonment. Losses are indicated by the absence of suckle marks on potential lactating females and by the departure of babysitters. The first day of emergence is noted in the life-history records [80] with successful litter emergence requiring minimally one surviving pup.

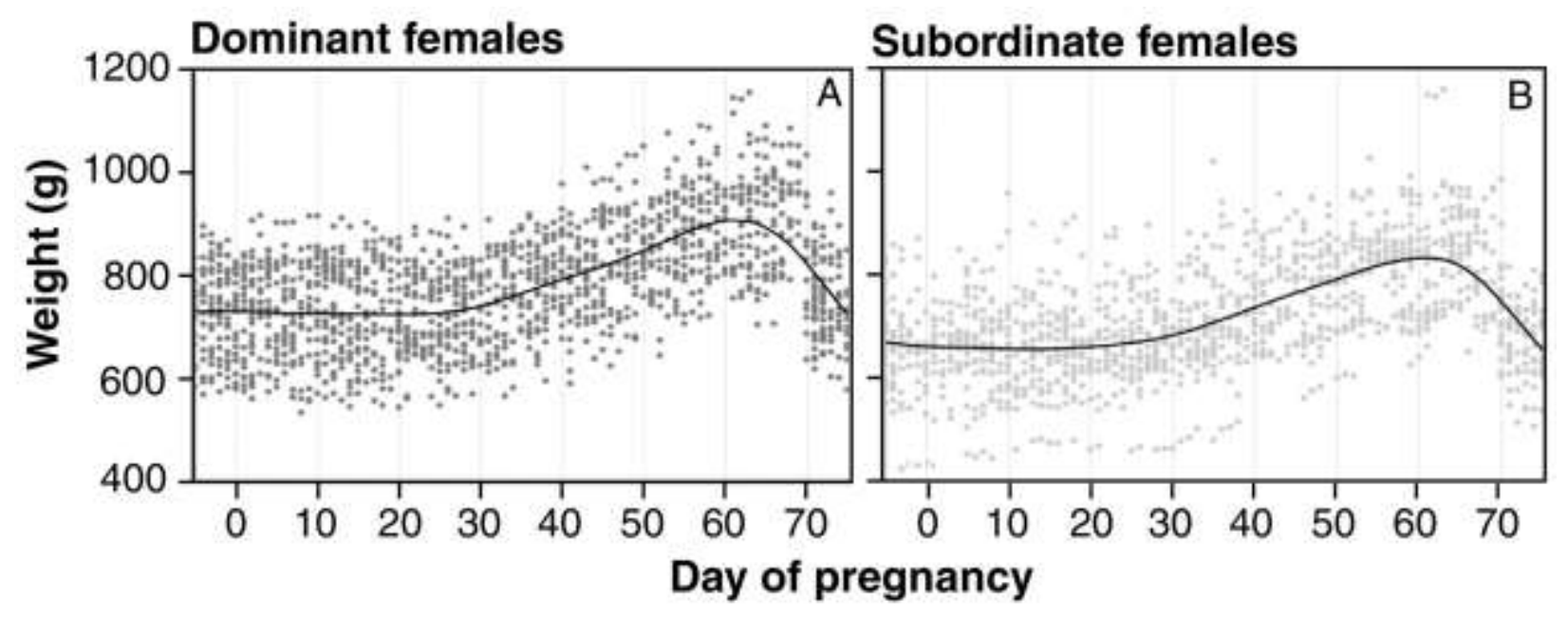

Fig. 1. Distribution, throughout the 41-month period of study, of first morning weights (in g), and median trendline, across the 70-day gestation of all focal (A) dominant and (B) subordinate female meerkats that carried their pregnancies to term. Parturition at day 70 is characterized by precipitous weight loss. 


\subsection{Estimating conception dates}

We estimated the date of conception for successful or full-term pregnancies (hereafter 'term' pregnancies) by backdating 70 days from the known date of birth [81]. Given that there is variation in the timing of pregnancy detection across studies (e.g. from 30 - 40 days of gestation $[60,61,82])$, possibly owing to differences in environmental variables affecting female condition, we created weight charts of contemporaneous, term pregnancies to inform our estimations of conception dates for pregnancies resulting in abortion (Figure 1). We used only morning weights (obtained between 0500-0900 H) and created separate charts for dominant and subordinate dams (because dominant animals are usually the oldest and heaviest) [27,47]. These charts show that the inflection point for observable weight gain during our study period occurred, on average, at roughly 30 days for all females, regardless of social status. For term pregnancies, this timing accorded well with the initial observations of shape changes.

For females that aborted, however, individual weight gain was not always apparent or occurred later than the observed shape change. The earliest abortion witnessed (estimated at 2325 days) fell on the cusp between the first two trimesters and occurred without any other observable changes being detected. The latest abortion witnessed occurred at full term (estimated at 70 days). Given that it occurred above ground, we considered it an abortion rather than a stillbirth. Comparisons against term pregnancies, coupled with weight and shape changes, and witnessed abortions, helped us validate our estimations of conception dates for aborted litters. Nevertheless, we report data for term pregnancies and abortions categorically, by 'trimesters' of roughly 23-day intervals (hereafter early, mid, and late pregnancy), rather than by continuous gestation day. 


\subsection{Serum and fecal sampling}

We obtained serum $(n=89)$ and fecal $(n=246)$ samples during gestation and/or the post pregnancy period (see figures 2 and 3 for the breakdown of serum and fecal samples, respectively, by female status and reproductive stage, that were included in the analyses). Our animal capture, blood and fecal collection, and sample processing procedures have been provided previously $[55,83]$. Briefly, we individually captured the focal meerkat in the morning, upon emergence from the sleeping burrow, anesthetized her with isoflurane (Isofor; Safe Line Pharmaceuticals, Johannesburg, South Africa), and collected 0.2-2 $\mathrm{ml}$ of blood from the jugular vein. Mean capture-to-bleed time was 7 minutes 39 seconds; neither $\mathrm{P}_{4}$ nor $\mathrm{E}_{2}$ concentrations varied as a function of capture-to-bleed time (both $p$ values $>0.68$ ). We immediately transferred the sample to a serum separator tube (Vacutainer®, Becton Dickinson, Franklin Lakes, NJ, USA) and allowed clotting at ambient temperature. We processed the blood samples and stored the serum on site at $-80{ }^{\circ} \mathrm{C}$ until transport, frozen, to Duke University in Durham, North Carolina, where we again kept them at $-80{ }^{\circ} \mathrm{C}$ until analysis. Because some of the blood samples had previously been assayed for other hormones [55], we prioritized the assay of $\mathrm{E}_{2}$ over $\mathrm{P}_{4}$ when remaining serum volumes were limited. Barring the excluded values (see below), our analyses culminated in $58 \mathrm{P}_{4}$ and $84 \mathrm{E}_{2}$ values. 


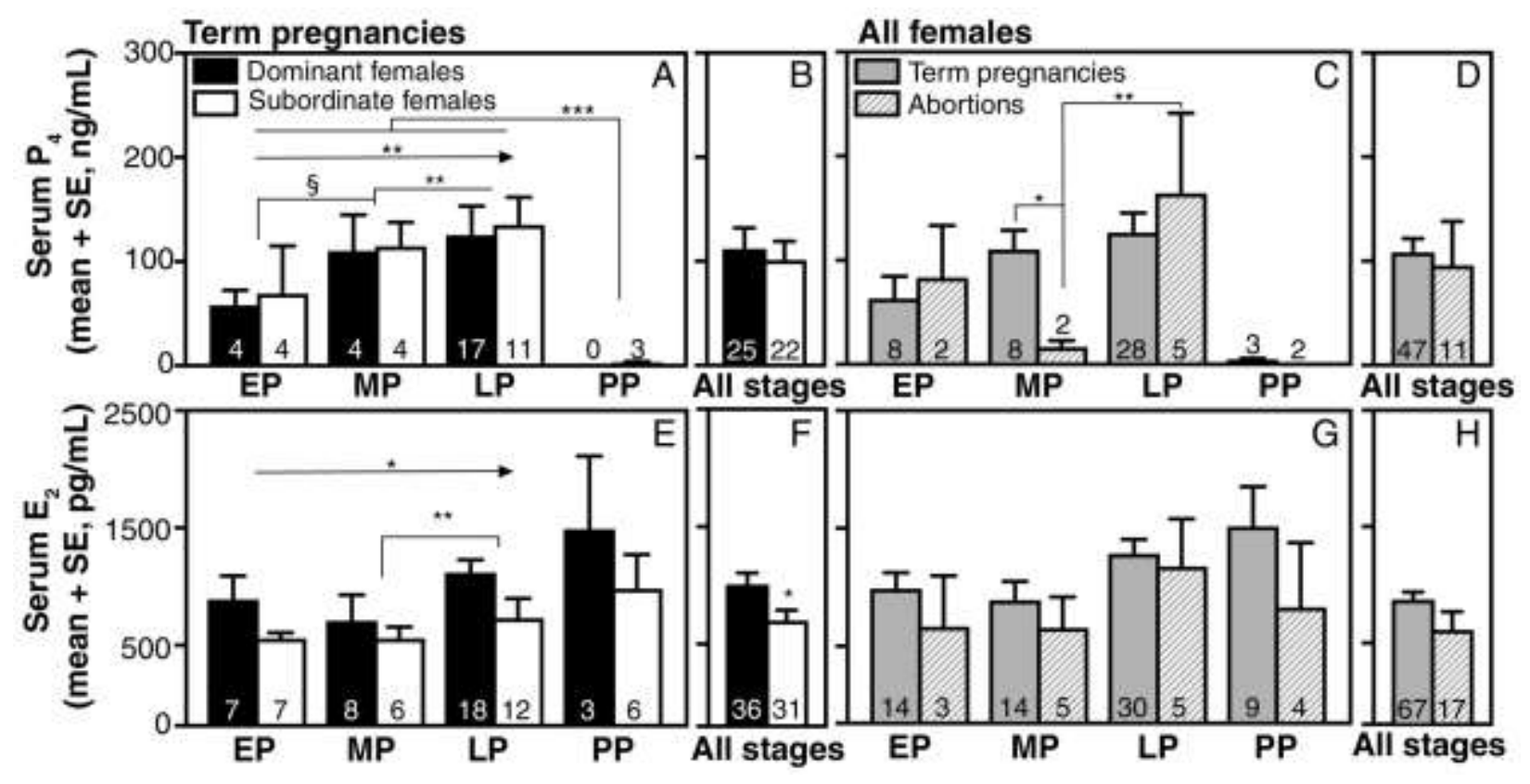

Fig. 2. Mean \pm S.E. serum concentrations of progesterone (A-D) and estradiol $(E-H)$ in dominant versus subordinate meerkats carrying full-term pregnancies (A-B, E-F), and in females of both social statuses combined carrying fullterm pregnancies versus pregnancies ending in mid- or late-term abortions (C-D, G-H). Shown, first by stage and then collapsed across stages, are hormone concentrations for samples collected during early ('EP'), mid ('MP'), and late ('LP') pregnancy, as well as post-pregnancy ('PP'). In A and E, the four stages represented would occur in chronological sequence for all females; in $\mathrm{C}$ and $\mathrm{G}$, the late-term stage of pregnancy would be absent for females aborting mid-term, such that their accompanying PP stage would be chronologically advanced. The number of samples contributing to each mean is provided at the bottom of the bars. $\S p<0.10, * p<0.05, * * p<0.01$, *** $p<$ 0.001 . 


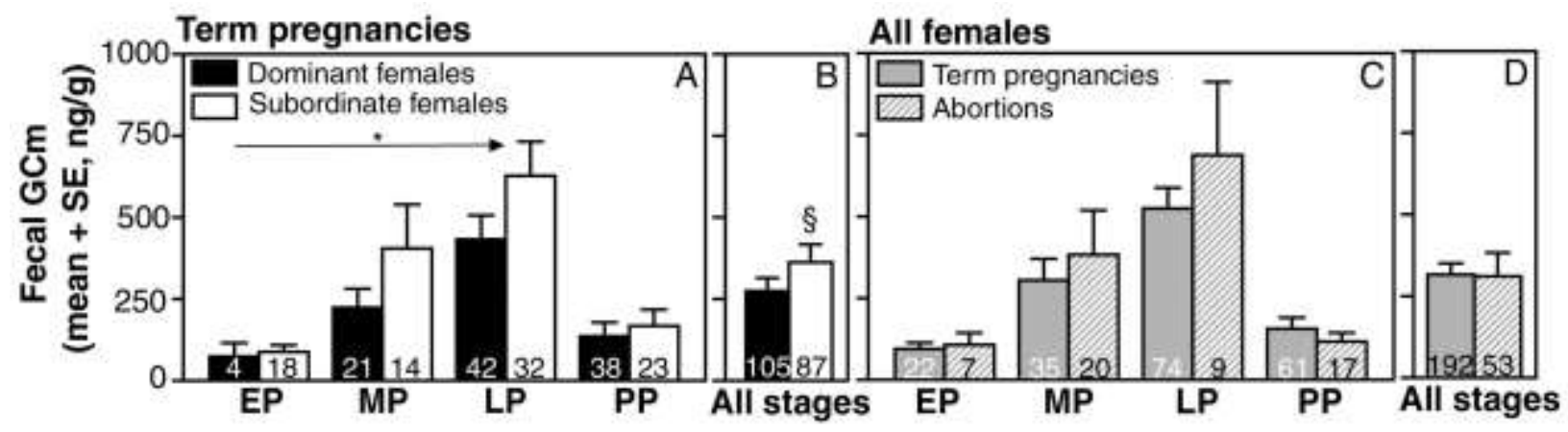

Fig. 3. Mean \pm S.E. concentrations of fecal glucocorticoid metabolites in dominant versus subordinate meerkats carrying full-term pregnancies (A, B) and in females of both social statuses combined carrying full-term pregnancies versus pregnancies ending in mid- or late-term abortions (C, D). Shown, first by stage and then collapsed across stages, are metabolite concentrations for samples collected during early ('EP'), mid ('MP'), and late ('LP') pregnancy, as well as post-pregnancy ('PP'). In A, the four stages represented would occur in chronological sequence for all females; in C, the late-term stage of pregnancy would be absent for females aborting mid-term, such that their accompanying post-pregnancy stage would be chronologically advanced. The number of samples contributing to each mean is provided at the bottom of the bars. $\S p<0.15, * p<0.05$.

Fecal sampling occurred ad libitum, throughout the day, during routine observational periods. We collected the fresh samples using clean plastic bags and immediately placed them on ice, in a cooler. Upon return from the field, we stored the samples at $-40{ }^{\circ} \mathrm{C}$ until transport, on ice, to Duke University, where we kept them at $-80{ }^{\circ} \mathrm{C}$ until assay.

Given the potential for an early post-partum estrus $[59,60]$, most of our post-pregnancy samples were obtained before 9 days. Nevertheless, to encompass the period from parturition to emergence and to have a post-pregnancy sampling period that was comparable in duration to a trimester, we included samples collected 9-20 days post-pregnancy if the female supplying the sample showed no signs of having conceived again during that time. We thus report on maximally four stages per pregnancy: three trimesters, plus the early post-pregnancy period. 


\subsection{Endocrine assays}

We determined serum concentrations of $\mathrm{P}_{4}$ and $\mathrm{E}_{2}$ using commercial, competitive enzyme immunoassay (EIA) kits (ALPCO diagnostics, Salem, NH, USA), following previously published procedures [55]. We validated the EIA serum assays by standard parallelism, linearity and recovery tests [84]. Samples with concentrations greater than the upper detection limit were diluted with assay buffer to no more than $1: 8$, and the results obtained were then multiplied by the dilution factor. Samples that had concentrations above the upper detectable limit of the assay after dilution were allocated the maximum value of eight times the upper detection limit. Samples that had concentrations below the minimum detectable limit of the assay were allocated the minimum value. All samples were run in duplicate and were re-run in a subsequent assay if the coefficient of variation (CV) exceeded $10 \%$.

The $\mathrm{P}_{4}$ assay has a sensitivity of $0.1 \mathrm{ng} / \mathrm{ml}$ using a $25-\mu 1$ dose, with an intra- and inter-assay CV of $10.4 \%$ and $11.4 \%$, respectively. Serial dilutions of pooled meerkat serum yielded a displacement curve parallel to the $\mathrm{P}_{4}$ standard curve. Accuracy was $106.2 \%(\mathrm{n}=5)$. Cross reactivity of the $\mathrm{P}_{4}$ assay was $100 \%$ with $11 \alpha-\mathrm{OH}$-progesterone, $1.7 \%$ with deoxycortocosterone, $0.4 \%$ with $17-\mathrm{OH}$-progesterone, $0.3 \%$ with $5 \alpha$-Androstan- $3 \beta, 17 \beta$-diol and corticosterone, $0.2 \%$ with pregnenolone, and $<0.1 \%$ with all other steroids tested. The $\mathrm{E}_{2}$ assay has a sensitivity of 10 $\mathrm{pg} / \mathrm{ml}$ using a $50-\mu \mathrm{l}$ dose, with an intra- and inter-assay $\mathrm{CV}$ of $7.7 \%$ and $8.7 \%$, respectively. Serial dilutions of pooled meerkat serum yielded a displacement curve parallel to the $\mathrm{E}_{2}$ standard curve. Accuracy was $104.2 \%(n=6)$. Cross reactivity of the $\mathrm{E}_{2}$ assay was $1.6 \%$ with estriol, $1.3 \%$ with estrone, and $0.1 \%$ with $\mathrm{P}_{4}$ and cortisol.

To prepare fecal samples for analysis, we lyophilized, pulverized, and sifted them into a fine powder within six months of collection, and stored the powder in vials at $-80{ }^{\circ} \mathrm{C}$ until extraction 
[83]. We extracted fecal glucocorticoid metabolites (fCGm) following previously described procedures $[85,86]$. Briefly, these extracts were assayed using the ImmuChem double-antibody

${ }^{125}$ I radioimmunoassay kit for corticosterone (MP Biomedicals, Irvine, CA), previously validated for use in a variety of avian and mammalian species [86], including meerkats [60,87]. Cross reactivity of the corticosterone assay was $0.34 \%$ with desoxycorticosterone, $0.10 \%$ with testosterone, $0.05 \%$ with cortisol, $0.03 \%$ with aldosterone, $0.02 \%$ with $\mathrm{P}_{4}, 0.01 \%$ with androstenedione and $5 \alpha$-dihydrotestosterone, and $<0.01 \%$ with all other steroids tested. The minimum detectable dose was $7.7 \mathrm{ng} \mathrm{ml}^{-1}$. Consistent with the validated protocol, we ran all volumes at one-half the recommended volumes for the kit. Assay accuracy, assessed by the recovery of standards added in duplicate to an extracted fecal sample, was $100.075 \%( \pm 6.528$ SD). Serial dilution of an extracted sample produced curves parallel to the standard curve. Interassay CVs were $10.93 \%$ and $9.05 \%$ for low and high fecal pools, respectively. Intra-assay CV, calculated as the mean $\mathrm{CV}$ of duplicate determinations, was 5.55\%. All individual sample CVs were below $15 \%$.

\subsection{Statistical analyses}

We analyzed serum $\left(\mathrm{P}_{4}\right.$ and $\left.\mathrm{E}_{2}\right)$ and fecal ( $\mathrm{fGCm}$ ) hormone concentrations using linear mixed models (LMMs) with the lme4 package (version 1.1-13) in the program R (version 3.4.1, R Core Team, 2017). In our dataset, observations could potentially be clustered at three levels: repeated sampling within pregnancy, multiple pregnancies within individuals, and individuals within social groups. To account for these sources of non-independence, random intercepts were modeled for group identity, individual dam identity, as well as pregnancies nested within individuals. We $\log$ transformed $\mathrm{P}_{4}, \mathrm{E}_{2}$, and fGCm values prior to analysis to reduce skewness; 
one outlier for $\mathrm{E}_{2}$ that remained after $\log$ transformation was Winsorized to limit its influence on model estimates. In our models predicting hormone concentrations, main effects and the twoway interaction between social status (dominant vs. subordinate) and pregnancy trimester (3 levels) or stage (4 levels, for trimesters plus post pregnancy) were examined. Included as covariates were average monthly rainfall preceding sample collection, average clan size during the dam's pregnancy, the dam's lactational status and age at the time of sample collection, and mean morning weight of the dam in the week leading to sample collection (mean number of weight readings $=3.34$ ). All fixed factors were assessed for statistical significance using $t$ or $F$ statistics and degrees of freedom (Satterthwaite approximation) estimated in the lmerTest package (version 2.0-33). To confirm the robustness of our models, we verified the normality of residuals using Q-Q plots and Shapiro-Wilk tests. The multcomp package (version 1.4-6) was used to test the significance of post hoc contrasts; this package provides adjusted $p$ values for multiple comparisons using Tukey's method.

For analyses assessing the relationship between term pregnancies and sex steroids, we excluded two blood samples collected post eviction (because eviction can minimally affect fGCm concentrations) [60]; nevertheless, we present those absolute values separately in the results. For analyses assessing the relationship between abortion and sex steroids, we excluded two outlier, post-pregnancy blood samples, collected the day after abortion from the same female, once while she was dominant and once while she was subordinate, because her $\mathrm{P}_{4}$ and $\mathrm{E}_{2}$ values were exceptionally high (possibly because sex steroids generated during pregnancy had not yet cleared). For analyses of glucocorticoids, we excluded two samples that yielded invalid values in our radioimmunoassay: one of these samples consistently yielded values below the 
range of our standard curve, regardless of dilution; conversely, the other sample consistently exceeded our range of detectability, regardless of sample concentration.

\subsection{Ethics statement}

Our protocols were approved by the University of Pretoria ethics committee (Ethical Approval Numbers EC074-11 and EC080-14) and the Duke University Institutional Animal Care and Use Committee (Protocol Registry Numbers A171-09-06 and A143-12-05).

\section{Results}

\subsection{Maternal factors in fetal and neonatal outcomes during and prior to the drought}

Of the pregnancies we monitored, $74 \%$ (105/141) were carried to term, whereas $26 \%$ (36/141) ended in either mid- or late-term abortion (Table 1). Controlling for maternal status and stage of the pregnancy, term pregnancies were marked by significantly heavier maternal weights than were aborted pregnancies $\left(t_{160}=2.10, p<0.038\right)$. Of the pregnancies borne by dominant versus subordinate females, $21 \%(14 / 67)$ and $30 \%$ (22/74), respectively, ended in spontaneous abortion. Subordinate dams residing within their clan were thus 1.6 times more likely than dominant dams to abort (odds ratio); however, this difference was not statistically significant (Fisher's Exact test, two-tailed: $p=0.2514$ ).

In an earlier study conducted prior to the drought [61], 18\% (49/259) of the pregnancies borne by dominant females and 33\% (110/331) of the pregnancies borne by subordinate females ended in spontaneous abortion. Applying our same analytical approach to that earlier dataset, we see that subordinate dams were 2.1 times as likely as dominant dams to abort, which is a statistically significant difference (Fisher's Exact test, two-tailed: $p=0.0001$ ). Comparing across 
studies, we found that the two sets of dominant dams were equally as likely to abort (present study 1.2 times > prior study; $p=0.8633$ ); the same was true for the two sets of subordinate dams (prior study 1.2 times $>$ present study; $p=0.5866$ ).

Of the pregnancies that were carried to term in the present study, 34\% (36/105) of the resulting litters failed to emerge from the natal den (Table 1). Controlling for maternal social status, postpartum periods in which the litters were lost were marked by non-significantly greater maternal weights, compared to ones in which the litter emerged $\left(t_{37}=1.676, p=0.1021\right)$. Of the litters born to dominant females ('dominant litters'), 28\% (15/53) were lost pre-emergence versus $40 \%$ (21/52) lost pre-emergence from subordinate females ('subordinate litters'). Subordinate litters were thus 1.7 times more likely than dominant litters to be lost (odds ratio); however, this difference was not statistically significant (Fisher's Exact test, two-tailed: $p=$ $0.2213)$.

Again, if we apply the same analytical approach to the earlier dataset [61], in which 13\% $(31 / 230)$ and $70 \%(146 / 207)$ of dominant and subordinate litters, respectively, were lost preemergence, we see that during the prior study, subordinate litters were 15.2 times more likely than dominant litters to be lost pre-emergence (Fisher's Exact test, two-tailed: $p<0.0001$ ). Comparing across studies, dominant litters were 2.5 times more likely to be lost during the present drought years than during the prior study (Fisher's Exact test, two-tailed: $p=0.0127$ ), whereas the reverse was true for subordinate litters, which were 3.5 times more likely to be lost during the prior study than during the present drought years (Fisher's Exact test, two-tailed: $p<$ 0.0001). Thus, this environmental stressor predicted litter emergence more strongly than it predicted a female's ability to carry her litter to term and, relative to prior years, it exacted a relatively greater toll on dominant females than it did on subordinates. 
Combining abortions with postnatal loss for the present study, minimally $51 \%((36+36) / 141)$ of all recognized breeding attempts failed (Table 1). Whereas dominant females experienced a $43 \%((14+15) / 67)$ failure rate, subordinate females experienced a $58 \%((22+21) / 74)$ failure rate. Although reproductive failure was 1.8 times more likely for subordinate dams than for dominant dams, the difference was not statistically reliable (Fisher's Exact test, two-tailed: $p=0.0928$ ). By comparison, during the prior study, dominant females experienced a $29 \%((49+31) / 279)$ failure rate and subordinate females experienced an $81 \%((110+146) / 317)$ failure rate, such that reproductive failure was 10.3 times more likely for subordinate dams than for dominant dams (Fisher's Exact test, two-tailed: $p<0.001$ ). The drought thus appeared to equalize the otherwise strong reproductive skew that typically characterizes female meerkats.

\subsection{Serum progesterone during and after successful and aborted pregnancies}

During the present study, pregnancy in meerkats was associated with overall differences across gestation in serum $\mathrm{P}_{4}$ concentrations (main effect of trimester: $F_{2,32}=5.57, p=0.008$; Figure $2 \mathrm{~A}) . \mathrm{P}_{4}$ increased marginally from early to mid-gestation $\left(t_{32}=2.07, p=0.096\right)$, and significantly from mid to late gestation $\left(t_{32}=2.93, p=0.009\right.$; Figure 2A). Concentrations of $\mathrm{P}_{4}$ then decreased significantly and precipitously following parturition (contrast between the mean of the three trimesters and the postpartum period: $t_{38}=5.31, p<0.001$; Figure 2A). Mean $\mathrm{P}_{4}$ concentrations across pregnancies did not differ between dominant and subordinate dams (main effect of status: $F_{1,32}=0.57, p=0.455$ ), nor were there status differences in $\mathrm{P}_{4}$ during individual periods of observation (status $\mathrm{x}$ stage interaction: $F_{3,34}=0.34, p=0.711$; all pairwise contrasts $p$ $>0.46$; Figures $2 \mathrm{~A}$ and $2 \mathrm{~B}$ ). Lastly, relative to younger dams, older dams had significantly lower mean $\mathrm{P}_{4}$ concentrations (main effect of age: $t_{34}=-2.45, p=0.020$ ). 
The gestational increase in $\mathrm{P}_{4}$ reported above was qualified by a significant interaction between trimester and pregnancy outcome $\left(F_{2,32}=5.62, p=0.008\right)$. Relative to dams that carried their litters to term, those that spontaneously aborted did not have lower $\mathrm{P}_{4}$ concentrations, on average, across pregnancy (main effect of outcome: $F_{1,32}=0.50, p=0.484$ ); however, their trajectories of $\mathrm{P}_{4}$ across pregnancy differed (Figures $2 \mathrm{C}$ and 2D). Noteworthy in females that aborted was a substantial and significant reduction in $\mathrm{P}_{4}$ at mid gestation, relative both to midgestation values in full-term pregnancies $\left(t_{34}=-3.15, p=0.016\right)$ and to the third trimester of aborted pregnancies (early - mid: $t_{34}=2.09, p=0.247$; mid - late: $t_{34}=-3.68, p=0.002$; Figure 2C). Concentrations of $\mathrm{P}_{4}$ in early and late pregnancy did not differ as a function of the pregnancy's outcome (both pairwise comparisons $p<0.60$; Figure 2C).

\subsection{Serum estradiol during and after successful and aborted pregnancies}

In pregnant meerkats, serum $\mathrm{E}_{2}$ concentrations differed significantly across trimesters (main effect of trimester: $\left.F_{2,50}=4.40, p=0.017\right)$, showing no change from early to mid gestation $\left(t_{50}=\right.$ $-0.63, p=0.805)$, but increasing significantly from mid to late gestation $\left(t_{50}=2.96, p=0.009\right.$; Figure 2E). In contrast to our findings for $\mathrm{P}_{4}$, dams in the postpartum period maintained substantial $\mathrm{E}_{2}$ concentrations that did not differ from their $\mathrm{E}_{2}$ concentrations averaged across gestation $\left(t_{64}=-0.45, p=0.656\right.$; Figure $\left.2 \mathrm{E}\right)$. Relative to younger dams, older dams had marginally lower mean $\mathrm{E}_{2}$ concentrations (main effect of age: $t_{54}=-1.69, p=0.096$ ). Post eviction, the two excluded subordinate females that carried to term, but ultimately lost their litters, had late-term $E_{2}$ concentrations of 340 and $766 \mathrm{pg} / \mathrm{ml}$, which were within the range of variation observed in late-term subordinates that were not evicted. 
Overall, $\mathrm{E}_{2}$ concentrations were significantly greater in dominant than in subordinate dams (main effect of social status: $F_{1,52}=4.50, p=0.039$; Figure $2 \mathrm{~F}$ ). These status differences were consistent across trimesters (status $\mathrm{x}$ trimester interaction: $F_{2,50}=1.51, p=0.231$ ) and across all periods of observation (status $\mathrm{x}$ stage interaction: $F_{3,57}=0.62, p=0.602$; Figures $2 \mathrm{E}$ and $2 \mathrm{~F}$ ).

Across our four periods of observation, relative to pregnancies that were carried to term, those that resulted in fetal loss were marked by somewhat lower $\mathrm{E}_{2}$ concentrations (main effect of outcome: $F_{1,58}=2.47, p=0.122$ ), but similar $\mathrm{E}_{2}$ trajectories (outcome $\mathrm{x}$ stage interaction: $F_{3,55}$ $=1.47, p=0.233$; all pairwise comparisons $p>0.83$; Figures $2 \mathrm{G}$ and $2 \mathrm{H}$ ).

\subsection{Fecal glucocorticoids during and after successful and aborted pregnancies}

In our sample of pregnant dams, fGCm concentrations differed significantly across gestation (main effect of trimester: $F_{2,134}=4.10, p=0.019$ ), with non-significant increases from early to mid-gestation $\left(t_{134}=0.28, p=0.957\right)$ and from mid to late-gestation $\left(t_{213}=-1.26, p=0.415\right)$; fGCm then tended to decrease, albeit not significantly, following parturition $\left(t_{213}=-1.58, p=\right.$ 0.117; Figure 3A). Thus, peak fGCm values occurred in late gestation.

Concentrations of fGCm were consistently greater in subordinate females than in dominant females; this status difference was marginally significant during pregnancy $\left(F_{1,134}=3.36, p=\right.$ 0.069), but became less reliable when comparing across all four observation periods $\left(F_{1,159}=\right.$ 2.25, $p=0.136$; Figures 3A and 3B).

Across periods of observation, fGCm concentrations did not differ in pregnancies ending in abortion, compared to term pregnancies $\left(F_{1,187}=0.31, p=0.579\right.$; Figures $3 \mathrm{C}$ and $\left.3 \mathrm{D}\right)$. 


\subsection{Reproductive and stress hormones in relation to environmental variables}

Group size has been associated with the suppression of meerkat reproduction, such that the frequency of abortions in subordinate females increases in larger clans [61]. From our model, pregnancy outcome (controlling for female status) was modestly associated with group size ( $t_{251}$ $=-1.668, p=0.097$ ), with pregnancies ending in abortion occurring in clans that had an average of 0.9 more members than the clans in which pregnancies were carried to term. There was, however, no relation between group size and female weight $\left(F_{1,98}=0.26, p=0.611\right)$. Together, these findings could suggest that subordinates experience greater stress in larger groups; however, we found no significant relation between group size and any hormone concentrations across the three trimesters $\left(\mathrm{P}_{4}: F_{1,32}=1.60 ; \mathrm{E}_{2}: F_{1,50}=-0.35\right.$; fGCm: $F_{1,134}=1.22 ;$ all $\left.p \mathrm{~s}>0.21\right)$ nor between gestation and the post-pregnancy period ( $\mathrm{P}_{4}: F_{1,34}=0.39 ; \mathrm{E}_{2}: F_{1,56}=0.08$; fGCm: $F_{1,167}=1.78 ;$ all $\left.p s>0.18\right)$ in either term or aborted pregnancies.

Under the present drought conditions, pregnant females had mean fGCm concentrations of 96, 331, 542, and $134 \mathrm{ng} / \mathrm{g}$ of feces during the early-, mid-, late-, and post-pregnancy stages, respectively. By comparison, prior to the drought, peak late-gestation fGCm values for pregnant females from this same population, calculated using the same assay procedure, averaged 305 $\mathrm{ng} / \mathrm{g}$ of feces [59]. Thus, although we observed a typical pattern of increase in $\mathrm{fGCm}$ concentrations across gestation (Figure 3), during the period of peak concentrations, the absolute values recorded during the drought were raised roughly twofold relative to those recorded during a prior study period. Unfortunately, a similar comparison for sex steroids was not possible because serum concentrations at any gestational stage are unavailable for earlier studies. 


\section{Discussion}

\subsection{Spontaneous abortion and neonatal loss in wild meerkats during an environmental stressor}

During an extended drought in the Kalahari, roughly $26 \%$ of the pregnancies observed in a wild meerkat population ended in mid- or late-term abortion - a rate that is within the expected range of values by comparison with other mammalian species (wild or domestic) [67,68,88-91]. More specifically, the incidences of fetal loss by maternal social status (i.e., $21 \%$ versus $30 \%$ for dominant and subordinate dams, respectively) were comparable to, if slightly less disparate than, those previously reported for the same meerkat population during less arid conditions (i.e., $18 \%$ and 33\%, respectively) [61]. Under limited rainfall, and hence limited dietary resources, we had expected a greater percentage of abortions than that previously reported [61]; however, we noted that some of our dams failed to gain weight, which may have predisposed them to fetal loss and, if symptomatic of the drought, may have limited our ability to detect other pregnancies before they terminated. Indeed, under drought conditions, pregnancies that ended in spontaneous abortion were marked by lower average weights than during term pregnancies. Moreover, across mammals, when abortions are detectable at all stages of prenatal development, early loss occurs most commonly $[88,89]$ and is most strongly associated with maternal stress $[75,92]$. Given that we lack information on embryonic loss or early fetal reabsorption in meerkats (although see [80]), we may be routinely underestimating both the occurrence of fetal loss and the impact of maternal stress.

In contrast to abortion rates, the occurrence of pre-emergence losses (i.e., 34\%) following pregnancies carried to term during the drought (experienced at $28 \%$ and $40 \%$ by dominant and subordinate females, respectively) differed proportionally from an earlier period of study (experienced at $13.5 \%$ and $70.5 \%$ by dominant and subordinate females, respectively [61]). 
Although pregnancy is energetically costly to females, it is less costly than lactation [93-95] and this cost differential may help explain why we observed seemingly less impact of the drought on abortion than on neonatal loss. Nevertheless, the absence of a relation between litter outcome and maternal weight might suggest that, in cooperative breeders, the potential for shared burden via allonursing may help offset the anticipated cost of lower maternal weight during a period of food restriction.

Combining abortions with postnatal loss, minimally $51 \%$ of litters conceived during the course of our study perished before emergence, comparable to the $56 \%$ of conceived litters that failed during an earlier period of study [61]. Nevertheless, the percentages of reproductive failure experienced by our dominant (43\%) and subordinate (58\%) females were much less disparate than those during the prior study (i.e., $29 \%$ and $81 \%$ for dominant and subordinate females, respectively [61]). To the extent that the subset of pregnancies we monitored was representative of the larger population and that the absence of significant status-related differences in survivorship would persist at later ages, the drought may well have contributed to temporarily reduce or even eliminate the reproductive skew between dominant and subordinate females, both by increasing the relative failure experienced by dominant females and by lessening the relative failure experienced by subordinates.

\subsection{Variability in singular versus plural cooperative breeding}

Our findings highlight the potential for fluidity within species [49], in this case between singular and plural cooperative breeding. Evidence of this fluidity in meerkats had been observed previously in relation to the effects of group size on subordinate abortion rates [61], implying that the reproductive success of subordinate meerkats (i.e., plural vs. singular breeding) varies 
between clans as a function of their membership numbers [28]. Here, owing to continuous, longterm study of the same population [96], we propose that the range of influential factors should include extreme variability in rainfall. Perhaps what these two factors have in common is that they influence the dynamics of within-group competition, albeit in different ways.

Although we dichotomized the various studies (i.e., ours versus those conducted during earlier periods) into drought versus 'non-drought,' the effects of environmental variables on reproductive skew likely occur along a continuum. Under the harshest conditions, reproductive skew could be 'equalized' merely as a function of widespread infant mortality. Indeed, in our second year of study, only one infant ultimately survived to one year of age, drawing attention to the negative implications of climate change for animal conservation. Luckily, such high rates of mortality were not always the case, such that our findings fell along, rather than at the end of, this ostensible continuum.

Factors other than increased mortality, therefore, contributed to explaining variation in reproductive skew: First, although 'rank has its privileges,' those privileges are not uniform across social species. Even within cooperative breeders, social dominance can facilitate priority of access to reproductive and feeding opportunities in some species (e.g. group hunting canids), but mainly to reproductive opportunities for other species (e.g. independently foraging herpestids). Meerkats, whose access to resources is determined more by their foraging efficiency than by their social standing, may be relatively immune from status-associated food deprivation and its consequences on reproductive success. One might not expect the same outcome on reproductive skew in other species (such as many primates) for which social hierarchies determine access to resources. Second, the exceptionally high rate of reproduction in dominant female meerkats likely becomes unsustainable when environmental conditions are unfavorable. 
Beyond limiting their own reproduction (and potentially their associated aggressiveness toward pregnant subordinates), the slowed reproductive pace of dominant females may have provided a window of opportunity for subordinates to reproduce. When conditions are unfavorable, survival of any offspring becomes crucial for sustaining clan numbers and providing the future helpers so essential to obligate cooperative breeders.

\subsection{Reproductive endocrine correlates of meerkat pregnancy and abortion}

Consistent with a preliminary study in meerkats [81] and with patterns observed in other species (carnivores [97,98]; primates $[19,99,100]$ ), we found an increase in serum $\mathrm{P}_{4}$ concentrations across gestation, followed by a precipitous decline at parturition. This pattern was comparable between dominant and subordinate females. As in some species [6], but unlike in others $[15,19]$, fetal loss in meerkats was associated with a significant dip in $\mathrm{P}_{4}$ concentrations mid gestation. Because this finding is based on a small number of samples, it warrants further investigation. Given the negative influence of glucocorticoids on gestational $\mathrm{P}_{4}[17,76,77,101$, 102], this effect could be indicative of an influence of maternal stress.

In prior reports on meerkats $[55,81], \mathrm{E}_{2}$ concentrations increased significantly during pregnancy, relative to baseline preconception values. In the current study, we found less substantial increases across trimesters: $\mathrm{E}_{2}$ concentrations in pregnant meerkats, albeit routinely lower in subordinate than in dominant dams, were consistently raised (> $600 \mathrm{pg} / \mathrm{ml}$ ) and, oddly, increased even further postpartum. Overall, this pattern bears little resemblance to that observed in other species, for which $\mathrm{E}_{2}$ concentrations tend to be low (e.g. $<100 \mathrm{pg} / \mathrm{ml}$ ) in the first trimester, increase more dramatically later in gestation, and then decline precipitously postpartum $[19,21,71,89,99,100,103]$. The unusually high postpartum $\mathrm{E}_{2}$ concentrations of 
meerkats, observed in seemingly few other species (e.g. [104]), are unlikely to be associated with lactation demands, given that even spontaneously lactating mongooses show minimal increases in $E_{2}$ [105]. Perhaps, despite our efforts, we failed to exclude samples reflecting post-partum estrus, but this explanation seems unlikely. In various species, reduced $\mathrm{E}_{2}$ concentrations are predictive of fetal loss $[6,11,19]$ and, in our dataset, although the difference failed to reach statistical significance, female meerkats that ultimately aborted tended to have reduced $\mathrm{E}_{2}$ concentrations relative to females that carried pregnancies to term.

Although research interest has been understandably directed toward the potential association between status-related differences in $\mathrm{E}_{2}$ concentrations and meerkat reproductive skew, neither the female's LH concentrations following a gonadotrophin-releasing hormone challenge [57] nor the concentrations of $\mathrm{P}_{4}$ and $\mathrm{E}_{2}$ found here for full-term pregnancies reveal deficits in the endocrine substrates underlying reproductive function in subordinate females. Evidently, the relatively lower $\mathrm{E}_{2}$ concentrations in subordinate females are adequate for them to routinely bear live young. The present results are thus inconsistent with the idea that reproductive suppression in female meerkats is physiologically mediated by differences in $\mathrm{E}_{2}$ concentrations during gestation. Instead, differential reproduction may reflect differences in fertility more so than differences in fecundity. These results do not, however, negate a role for $\mathrm{E}_{2}$ in reproductive failure: a decrement below some threshold could become diagnostic of fetal loss, and the $\mathrm{E}_{2}$ concentrations of subordinates certainly would be closer to that threshold.

Perhaps rather than being indicative of physiological restraint or downregulation [56], reduced $\mathrm{E}_{2}$ concentrations in subordinate dams may be symptomatic of the females' statusrelated difference in concentrations of androgenic precursors to estrogens. Female meerkats of both social classes, albeit dominant females more so than subordinates, have exceptionally high 
concentrations (i.e., to the point of sex reversal) of androstenedione and testosterone, both during and outside of pregnancy [55]. Following aromatization, these androgens may contribute to the ample gestational $\mathrm{E}_{2}$ concentrations evident even in the first trimester, as well as during the postpartum period. It may be that, via facilitation of a dominant female's aggression toward subordinates, the status-related difference in androgen concentrations mediate purely behavioral mechanisms of reproductive suppression. Although this latter hypothesis remains to be tested, it draws attention, more broadly, to the need for better representation of heterologous hormones (e.g. androgens in females and estrogens in males) in the study of reproductive function and social interaction, particularly in female-dominant species $[55,98,99,106]$.

\subsection{Stress hormone correlates of meerkat pregnancy and abortion}

Consistent with patterns of nonpathological hypercortisolemia reported in other species, including many primates (reviewed in [107]), stress hormone concentrations increased across gestation in meerkat pregnancies. Glucocorticoids late in pregnancy are generally beneficial, contributing to fetal survival and live birth, and also to the dam's mammary epithelial expansion necessary for lactation [57]; nevertheless, excesses in glucocorticoids can become detrimental to the offspring $[59,102]$ and, if stressors become chronic, glucocorticoids can also compromise adult survival [108].

Several lines of evidence suggest that the absolute fGCm concentrations we detected in meerkats owed to their experience of an environmental stressor. Beyond the dams'significant weight loss noted earlier, all of the females had consistently raised fGCm values. Moreover, the peak fGCm values we recorded in late gestation exceeded by nearly twofold those of lategestation females during years prior to the drought [59]. Likewise, other temporary stressors, 
including eviction [60] and exposure to humans [109] in wild and captive meerkats, respectively, have been associated with increased fGCm concentrations, but with lower absolute values than those recorded here.

\subsection{Testing the biopsychosocial model in meerkats}

Our findings on the associations between socioecological factors and stress hormones contribute meaningfully to elucidating an inconsistent literature. In the first study of GCs in meerkats, dominant animals of both sexes were more likely than their subordinate counterparts to have measurable concentrations of plasma cortisol [55]. The authors inferred that any reproductive suppression in subordinate females, potentially associated with their reduced $\mathrm{E}_{2}$ and LH concentrations, could not be explained by circulating GCs [54]. In most later studies, researchers measured fecal GC concentrations. Barrette and colleagues [59] found no significant class differences, but reasoned that dominant females would nevertheless suffer from greater lifetime exposure to the augmented GCs associated with pregnancy, given their more frequent reproductive cycles and shorter inter-birth intervals relative to subordinates. Because handling significantly increases plasma cortisol in meerkats [63], perhaps the difference between studies owes to the manner in which GCs were assessed. It may be that no baseline differences in circulating GCs exist over the short term when measured noninvasively and under normal environmental conditions [59], but that, as previously shown for other species (e.g. [110]), members of the two social classes respond differently to an acute stressor of capture and anesthesia owing to existing differences in their cumulative exposure to reproductive stressors. These differences underscore the need to consider the effects of acute vs. accumulated stressors in future studies. 
Because subordinate females temporarily evicted from their clan suffered a roughly two-fold increase in fecal GCs and, if pregnant, in abortion rate relative to their subordinate counterparts that continued to reside within the clan, Young and colleagues [60] argued strongly in favor of the stress-related suppression hypothesis. Whatever the status-related patterns within the clan, the response to eviction established that subordinates are susceptible to socioecological stressors. With regard to subordinate males, Young and Monfort [111] similarly found that rovers subordinate males that temporarily leave their clan to prospect for reproductive opportunities and that often secure extra-group paternity [112] - also suffered a roughly two-fold increase in fecal glucocorticoids relative to their resident counterparts. Thus, departure from the group, whether voluntarily or forcibly, constitutes a significant stressor for these social animals, but apparently without the same deleterious reproductive consequences for males.

Although we found no significant differences by social status or pregnancy outcome, absolute fGCm concentrations were high and consistently greater in subordinate than dominant females. Our status-related findings on fGCm diverge from those presented in earlier studies, but are parsimonious with recent findings from a contemporaneous study, in which subordinates had high glucocorticoid concentrations under various social circumstances [63]. These findings suggest that there is flexibility in a system that balances reproductive tradeoffs between classes (e.g. [113]) under varying environmental conditions. As revealed by the reduced differential in female reproductive success, it may be that certain environmental stressors, such as food shortage, are experienced comparably between the classes. Nevertheless, as revealed by the unusual status-related patterns in fGCm, it may be that under prolonged conditions of high energetic demands [114], subordinates become susceptible to additional social stressors that 
otherwise remain latent, such as intensified food competition in large groups. Thus, there may be different consequences by class in response to climatic versus social stressors.

\section{Conclusion}

The study of fetal loss in wild populations is in its early stages, but can reveal important information about the social and ecological drivers of reproductive success. To date, field studies of fetal loss have been focused primarily on anthropoid primates that bear visible signs of estrus (such as exaggerated sex skin swellings), as these signs allow researchers to accurately estimate the timing both of conception and of fetal loss [22]. Many other species, however, including meerkats, have no such signs; nevertheless, the frequency and reliability with which we can obtain weight measurements on this habituated population and closely monitor abdominal swelling is unparalleled. These tools, gained as a benefit of long-term study [96], allowed us to determine fetal loss in later stages of gestation. Nonetheless, the necessarily retrospective nature of this kind of study hindered prospective sample collection.

Despite our limited sample sizes, particularly for aborted pregnancies, the combination of significant findings and suggestive trends paints a cohesive picture in keeping with the biopsychosocial model of fetal loss. Drought is a major environmental stressor $[107,114]$ that limits food supplies and exerts a toll on all animals. Regardless of the dam's social status, we observed a mean weight difference of $37 \pm 17 \mathrm{~g}$ (or roughly $4-7 \%$ of total body weight) between time-matched pregnancies carried to term and those ending in abortion. Stress-related abortions coupled with neonatal loss reduced the differential in reproductive success that typically characterizes the two social classes. This environmental stressor predicted smaller reproductive skew during the most energetically expensive time for a reproductive female: the period of post- 
partum lactation. More generally, such costs may be experienced more profoundly in cooperative breeders than in other species, increasing the probability of group extinction [115].

Endocrine biomarkers support our proposal of environmental stressor effects. Unusually high concentrations of stress hormones were evident throughout pregnancies, but were potentially even greater in subordinates, suggesting added social stressors experienced physiologically within the clan. These glucocorticoids may have dampened both $\mathrm{P}_{4}$ and $\mathrm{E}_{2}$, as occurs in other species. Nevertheless, the female meerkat's relatively and consistently high $\mathrm{E}_{2}$ concentrations throughout gestation and into the post-partum period, even in subordinates, are inconsistent with a role for $\mathrm{E}_{2}$ in reproductive failure post conception. Instead, they may be a byproduct of exceptionally high concentrations of androgenic precursors. Androgens, including androstenedione and testosterone, are prominent in all females, but greatest in dominant dams [55] and may underlie their aggression against pregnant subordinates [46]. This new perspective could shift future research emphasis from an endocrine mechanism of reproductive suppression functioning in subordinate females to an endocrine mechanism of behavioral masculinization functioning in dominant females.

Under normal climatic conditions, the stress experienced by an evicted female during social isolation [60] or associated with social subordination within a large clan [61] may create circumstances under which it is beneficial to disinvest in a fetus (e.g. [21]). In the absence of helpers, the litter of an evicted, obligate cooperative breeder would surely perish. Given the cost of lactation, aborting or abandoning a doomed litter is likely to be a coping mechanism that allows a female to minimize her losses, while also hastening her return to the group. Under severe climatic conditions, however, the stress associated with food restriction becomes an equalizer, such that all animals pay a reproductive cost. Regardless of the physiological 
mechanism underlying status-related differences in reproductive output, these data contribute to a growing number of studies showing the significant cost of environmental stressors and anthropogenic disturbance that could prove relevant to assessing the negative impact of climate change [116]. In particular, they highlight the value of mammalian field studies, conducted longterm in an ecological context, for understanding the social and life-history variables that help make these inferences possible $[96,117,118]$.

\section{Conflict of interest}

The authors declare no conflicts of interest.

\section{Funding}

This study was supported by the National Science Foundation (IOS-1021633 to C.M.D.) and vehicle costs in the field were supported by Duke University. We relied on records of individual identities and/or life histories maintained by the Kalahari Meerkat Project (KMP), which has been supported by European Research Council Grant (No 294494) to TCB and Swiss National Science Foundation Grant (31003A_13676) to M. Manser. During the span of this study, the KMP was supported by the University of Cambridge, the University of Zurich, the Mammal Research Institute at the University of Pretoria, and Duke University.

\section{Acknowledgements}

We are grateful to the Northern Cape for permission to conduct this research, to farmers neighboring the Kuruman River Reserve for allowing us to work on their land, and to the Trustees of the Kalahari Research Trust for use of facilities at the Kalahari Research Centre. We 
thank M.B. Manser for her support and input on the field work at the KMP, and M. Emery Thompson for helpful suggestions about endocrine assays. For their assistance with animal captures and blood draws, we thank the KMP managers, including S. Bischoff-Mattson, D.

Gaynor, L. Howell, L. Marris, J. Samson, and N. Tharavajah, and research colleagues, including N. Maag, J. Maud, S. Patterson, and D. Seager. Lastly, we are especially grateful to our project personnel, D. Blondel, M. Böddeker, S. Cox, V. Goerlich-Jansson, E. Kabay, D. Pfefferle, A. Reyes, K. Smyth, E. Terrade, and D. Walsh, as well as the KMP volunteers for assistance with animal monitoring and fecal sample collection.

\section{References}

1. Bishop, M. W. (1964). Paternal contribution to embryonic death. Journal of reproduction and fertility, 7(3), 383-396.

2. Mowbray, J. F. (1987). Genetic and immunological factors in human recurrent abortion. American journal of reproductive immunology and microbiology: AJRIM, 15(4), 138-140.

3. Beydoun, H., \& Saftlas, A. F. (2008). Physical and mental health outcomes of prenatal maternal stress in human and animal studies: a review of recent evidence. Paediatric and perinatal epidemiology, 22(5), 438-466.

4. Hytten, F. E., \& Leitch, I. (1964). The physiology of human pregnancy. The physiology of human pregnancy.

5. Kramer, M. S., Lydon, J., Séguin, L., Goulet, L., Kahn, S. R., McNamara, H., ... \& Meaney, M. J. (2009). Stress pathways to spontaneous preterm birth: the role of stressors, 
psychological distress, and stress hormones. American journal of epidemiology, 169(11), 1319-1326.

6. Nelson, D. B., Grisso, J. A., Joffe, M. M., Brensinger, C., Shaw, L., \& Datner, E. (2003). Does stress influence early pregnancy loss? Annals of epidemiology, 13(4), 223-229.

7. Sugiura-Ogasawara, M., Furukawa, T. A., Nakano, Y., Hori, S., Aoki, K., \& Kitamura, T. (2002). Depression as a potential causal factor in subsequent miscarriage in recurrent spontaneous aborters. Human Reproduction, 17(10), 2580-2584.

8. Clark, D. A., Banwatt, D., \& Chaouat, G. (1993). Stress-triggered abortion in mice prevented by alloimmunization. American Journal of Reproductive Immunology, 29(3), 141-147.

9. Joachim, R., Zenclussen, A. C., Polgar, B., Douglas, A. J., Fest, S., Knackstedt, M., ... \& Arck, P. C. (2003). The progesterone derivative dydrogesterone abrogates murine stresstriggered abortion by inducing a Th2 biased local immune response. Steroids, 68(10), 931940.

10. Schneider, M. L., Roughton, E. C., Koehler, A. J., \& Lubach, G. R. (1999). Growth and development following prenatal stress exposure in primates: an examination of ontogenetic vulnerability. Child development, 70(2), 263-274.

11. Tardif, S. D., Ziegler, T. E., Power, M., \& Layne, D. G. (2005). Endocrine changes in fullterm pregnancies and pregnancy loss due to energy restriction in the common marmoset (Callithrix jacchus). The Journal of Clinical Endocrinology \& Metabolism, 90(1), 335-339.

12. García-Ispierto, I., López-Gatius, F., Santolaria, P., Yániz, J. L., Nogareda, C., LópezBéjar, M., \& De Rensis, F. (2006). Relationship between heat stress during the periimplantation period and early fetal loss in dairy cattle. Theriogenology, 65(4), 799-807. 
13. Merlot, E., Quesnel, H., \& Prunier, A. (2013). Prenatal stress, immunity and neonatal health in farm animal species. Animal, 7(12), 2016-2025.

14. Omtvedt, I. T., Nelson, R. E., Edwards, R. L., Stephens, D. F., \& Turman, E. J. (1971). Influence of heat stress during early, mid and late pregnancy of gilts. Journal of Animal Science, 32(2), 312-317.

15. Czekala, N. M., Durrant, B. S., Callison, L., Williams, M., \& Millard, S. (1994). Fecal steroid hormone analysis as an indicator of reproductive function in the cheetah. Zoo Biology, 13(2), 119-128.

16. Sheriff, M. J., Krebs, C. J., \& Boonstra, R. (2009). The sensitive hare: sublethal effects of predator stress on reproduction in snowshoe hares. Journal of Animal Ecology, 78(6), 1249-1258.

17. Creel, S., Christianson, D., Liley, S., \& Winnie, J. A. (2007). Predation risk affects reproductive physiology and demography of elk. Science, 315(5814), 960-960.

18. Beehner, J. C., Onderdonk, D. A., Alberts, S. C., \& Altmann, J. (2006). The ecology of conception and pregnancy failure in wild baboons. Behavioral Ecology, 17(5), 741-750.

19. Beehner, J. C., Nguyen, N., Wango, E. O., Alberts, S. C., \& Altmann, J. (2006). The endocrinology of pregnancy and fetal loss in wild baboons. Hormones and behavior, 49(5), 688-699.

20. Kerhoas, D., Perwitasari-Farajallah, D., Agil, M., Widdig, A., \& Engelhardt, A. (2014). Social and ecological factors influencing offspring survival in wild macaques. Behavioral Ecology, 25(5), 1164-1172.

21. Roberts, E. K., Lu, A., Bergman, T. J., \& Beehner, J. C. (2012). A Bruce effect in wild geladas. Science, 335(6073), 1222-1225. 
22. Wasser, S. K., Norton, G. W., Rhine, R. J., Klein, N., \& Kleindorfer, S. (1998). Ageing and social rank effects on the reproductive system of free-ranging yellow baboons (Papio cynocephalus) at Mikumi National Park, Tanzania. Human Reproduction Update, 4(4), $430-438$.

23. Monfort, S. L. (2003). Non-invasive endocrine measures of reproduction and stress in wild populations. Conservation Biology Series-Cambridge-, 147-165.

24. Schwarzenberger, F., Möstl, E., Palme, R., \& Bamberg, E. (1996). Faecal steroid analysis for non-invasive monitoring of reproductive status in farm, wild and zoo animals. Animal Reproduction Science, 42(1-4), 515-526.

25. Clutton-Brock, T. H., \& Manser, M. (2016). Meerkats: cooperative breeding in the Kalahari. Cooperative breeding in vertebrates (eds WD Koenig, JL Dickinson), 294-317.

26. Doolan, S. P., \& Macdonald, D. W. (1999). Co-operative rearing by slender-tailed meerkats (Suricata suricatta) in the Southern Kalahari. Ethology, 105(10), 851-866.

27. Clutton-Brock, T. H., Brotherton, P. N., Russell, A. F., O'riain, M. J., Gaynor, D., Kansky, R., ... \& Small, T. (2001). Cooperation, control, and concession in meerkat groups. Science 291(5503), 478-481.

28. Doolan, S.P. \& Macdonald, D.W. (1997). Band structure and failures of reproductive suppression in a cooperatively breeding carnivore, the slender-tailed meerkat (Suricata suricatta). Behaviour, 134, 827-848.

29. Griffin, A. S., Pemberton, J. M., Brotherton, P. N., McIlrath, G., Gaynor, D., Kansky, R., ... \& Clutton-Brock, T. H. (2003). A genetic analysis of breeding success in the cooperative meerkat (Suricata suricatta). Behavioral Ecology, 14(4), 472-480. 
30. MacLeod, K. J., Nielsen, J. F., \& Clutton-Brock, T. H. (2013). Factors predicting the frequency, likelihood and duration of allonursing in the cooperatively breeding meerkat. Animal behaviour, 86(5), 1059-1067.

31. Clutton-Brock, T. (2016) Mammal Societies. Wiley-Blackwell

32. Emlen, S. T. (1991). The evolution of cooperative breeding in birds and mammals. In: Krebs, J. R., Davies, N. B., editors. Behavioural Ecology: An Evolutionary Approach, 3rd ed. Oxford: Blackwell, 301-37.

33. Jennions, M. D., \& Macdonald, D. W. (1994). Cooperative breeding in mammals. Trends in Ecology \& Evolution, 9(3), 89-93.

34. Koenig, W. D., \& Dickinson, J. L. (Eds.). (2004). Ecology and evolution of cooperative breeding in birds. Cambridge University Press.

35. Faulkes, C.G. \& Bennett, N.C. (2001). Family values: group dynamics and social control of reproduction in African mole-rats. TRENDS in Ecology \& Evolution 16(4): 184-190.

36. Jarvis, J.U.M. (1991). Reproduction of naked mole-rats. In: P.W. Sherman, J.U.M. Jarvis \& R.D. Alexander (eds.). The biology of the naked mole-rat, pp. 384-425. Princeton University Press, New Jersey.

37. French, J.A. (1997). Proximate regulation of singular breeding in callitrichid primates. In: N.G. Solomon \& J.A. French (eds.), Cooperative breeding in mammals, pp. 34-75. Cambridge University Press, Cambridge.

38. Creel, S., Creel, N.M., Mills, M.G.L. \& Monfort, S.L. (1997). Rank and reproduction in cooperatively breeding African wild dogs: behavioral and endocrine correlates. Behavioral Ecology 8: 298-306. 
39. Malcolm, J.R. \& Marten, K. (1982). Natural selection and the communal rearing of pups in African wild dogs (Lycaon pictus). Behavioral Ecology \& Sociobiology 10: 1-13.

40. Mech, L.D. (1970). The wolf: The ecology and behavior of an endangered species. Natural History Press, New York.

41. Clutton-Brock, T.H., Gaynor, D., McIlrath, G.M., MacColl, A.D.C., Kansky, R., Chadwick, P., Manser, M., Brotherton, P.N.M. \& Skinner, J.D. (1999). Predation, group size and mortality in a cooperative mongoose, Suricata suricatta. Journal of Animal Ecology 68: 672-683.

42. Clutton-Brock, T.H., Russell, A.F. \& Sharpe, L.L. (2004). Behavioural tactics of breeders in cooperative meerkats. Animal Behaviour 68: 1029-1040.

43. Clutton-Brock, T.H., Gaynor, D., Kansky, R., MacColl, A.D.C., McIlrath, G., Chadwick, P., Brotherton, P.N.M., O’Riain, J.M., Manser, M. \& Skinner, J.D. (1998). Costs of cooperative behaviour in suricates (Suricata suricatta). Proceedings of the Royal Society of London B 265: 185-190.

44. Clutton-Brock, T.H., Brotherton, P.N.M., O’Riain, M.J., Griffin, A.S., Gaynor, D., Sharpe, L., Kansky, R., Manser, M. \& McIlrath, G.M. (2000). Individual contributions to babysitting in a cooperative mongoose, Suricata suricatta. Proceedings of the Royal Society of London B 267: 301-305.

45. Clutton-Brock, T.H., O’Riain, M.J., Brotherton, P.N.M., Gaynor, D., Kansky, R., Griffin, A.S. \& Manser, M. (1999). Selfish sentinels in cooperative mammals. Science 284: 16401644. 
46. Clutton-Brock, T. H., Hodge, S. J., Spong, G., Russell, A. F., Jordan, N. R., Bennett, N. C., ... \& Manser, M. B. (2006). Intrasexual competition and sexual selection in cooperative mammals. Nature, 444(7122), 1065-1068.

47. Russell, A.F., Carlson, A.A., McIlrath, G.M., Jordan, N.R. \& Clutton-Brock, T.H. (2004). Adaptive size modification by dominant female meerkats. Evolution 58: 1600-1607.

48. Montgomery, T. M, Pendleton, E. L., \& Smith, J. E. Physiological mechanisms mediating patterns of reproductive suppression and alloparental care in cooperatively breeding carnivores. This volume.

49. Schradin, C., Vuarin, P., \& Rimbach, R. The neoteny-helper hypothesis: When to expect and when not to expect endocrine mechanisms to regulate allo-parental care? This volume.

50. Abbott, D. H. (1987). Behaviourally mediated suppression of reproduction in female primates. Journal of Zoology, 213(3), 455-470.

51. Abbott, D. H. (1984). Behavioral and physiological suppression of fertility in subordinate marmoset monkeys. American Journal of Primatology, 6(3), 169-186.

52. Faulkes, C. G., Abbott, D. H., \& Jarvis, J. U. M. (1990). Social suppression of ovarian cyclicity in captive and wild colonies of naked mole-rats, Heterocephalus glaber. Journal of Reproduction and Fertility, 88(2), 559-568.

53. Wasser, S. K., \& Barash, D. P. (1983). Reproductive suppression among female mammals: implications for biomedicine and sexual selection theory. The Quarterly Review of Biology, 58(4), 513-538.

54. Carlson, A. A., Young, A. J., Russell, A. F., Bennett, N. C., McNeilly, A. S., \& CluttonBrock, T. (2004). Hormonal correlates of dominance in meerkats (Suricata suricatta). Hormones and Behavior, 46(2), 141-150. 
55. Davies, C.S., Smyth, K.N., Greene, L.K., Walsh, D.A., Mitchell, J., Clutton-Brock, T.H. \& Drea, C.M. (2016). Exceptional endocrine profiles characterize the meerkat: sex, status, and reproductive patterns. Scientific Reports, 6, 35492.

56. Young, A. J., Monfort, S. L., \& Clutton-Brock, T. H. (2008). The causes of physiological suppression among female meerkats: a role for subordinate restraint due to the threat of infanticide? Hormones and behavior, 53(1), 131-139.

57. O’Riain, M. J., Bennett, N. C., Brotherton, P. N. M., McIlrath, G., \& Clutton-Brock, T. H. (2000). Reproductive suppression and inbreeding avoidance in wild populations of cooperatively breeding meerkats (Suricata suricatta). Behavioral Ecology and Sociobiology, 48(6), 471-477.

58. Clutton-Brock, T. H., Brotherton, P. N. M., Smith, R., McIlrath, G. M., Kansky, R., Gaynor, D., ... \& Skinner, J. D. (1998). Infanticide and expulsion of females in a cooperative mammal. Proceedings of the Royal Society of London B: Biological Sciences, 265(1412), 2291-2295.

59. Barrette, M. F., Monfort, S. L., Festa-Bianchet, M., Clutton-Brock, T. H., \& Russell, A. F. (2012). Reproductive rate, not dominance status, affects fecal glucocorticoid levels in breeding female meerkats. Hormones and behavior, 61(4), 463-471.

60. Young, A. J., Carlson, A. A., Monfort, S. L., Russell, A. F., Bennett, N. C., \& CluttonBrock, T. (2006). Stress and the suppression of subordinate reproduction in cooperatively breeding meerkats. Proceedings of the National Academy of Sciences, 103(32), 1200512010.

61. Clutton-Brock, T. H., Hodge, S. J., \& Flower, T. P. (2008). Group size and the suppression of subordinate reproduction in Kalahari meerkats. Animal Behaviour, 76(3), 689-700. 
62. Clutton-Brock, T. H., Hodge, S. J., Flower, T. P., Spong, G. F., \& Young, A. J. (2010). Adaptive suppression of subordinate reproduction in cooperative mammals. The American Naturalist, 176(5), 664-673.

63. Dantzer, B., Bennett, N. C., \& Clutton-Brock, T. H. (2017). Social conflict and costs of cooperation in meerkats are reflected in measures of stress hormones. Behavioral Ecology.

64. Packer, C., Collins, D. A., Sindimwo, A., \& Goodall, J. (1995). Reproductive constraints on aggressive competition in female baboons. Nature, 373(6509), 60-63.

65. Ruiz-López, M. J., Espeso, G., Evenson, D. P., Roldan, E. R., \& Gomendio, M. (2010). Paternal levels of DNA damage in spermatozoa and maternal parity influence offspring mortality in an endangered ungulate. Proceedings of the Royal Society of London B: Biological Sciences, 277(1693), 2541-2546.

66. Schlabritz-Loutsevitch, N. E., Moore, C. M., Lopez-Alvarenga, J. C., Dunn, B. G., Dudley, D., \& Hubbard, G. B. (2008). The baboon model (Papio hamadryas) of fetal loss: maternal weight, age, reproductive history and pregnancy outcome. Journal of medical primatology, 37(6), 337-345.

67. Turner, T. R., Whitten, P. L., Jolly, C. J., \& Else, J. G. (1987). Pregnancy outcome in freeranging vervet monkeys (Cercopithecus aethiops). American Journal of Primatology, 12(2), 197-203.

68. Wilmut, I., Sales, D. I., \& Ashworth, C. J. (1986). Maternal and embryonic factors associated with prenatal loss in mammals. Journal of Reproduction and Fertility, 76(2), $851-864$. 
69. Doolan, S. P., \& MacDonald, D. W. (1996). Diet and foraging behaviour of group-living meerkats, Suricata suricatta, in the southern Kalahari. Journal of Zoology, 239(4), 697716.

70. Albrecht, E. D., \& Pepe, G. J. (1999). Central integrative role of oestrogen in modulating the communication between the placenta and fetus that results in primate fetal-placental development. Placenta, 20(2-3), 129-139.

71. Albrecht, E. D., Aberdeen, G. W., \& Pepe, G. J. (2000). The role of estrogen in the maintenance of primate pregnancy. American journal of obstetrics and gynecology, 182(2), 432-438.

72. Arredondo, F., \& Noble, L. S. (2006, February). Endocrinology of recurrent pregnancy loss. In Seminars in reproductive medicine (Vol. 24, No. 01, pp. 033-039). Copyright $\odot$ 2006 by Thieme Medical Publishers, Inc., 333 Seventh Avenue, New York, NY 10001, USA.

73. Chida, D., Miyoshi, K., Sato, T., Yoda, T., Kikusui, T., \& Iwakura, Y. (2011). The role of glucocorticoids in pregnancy, parturition, lactation, and nurturing in melanocortin receptor 2-deficient mice. Endocrinology, 152(4), 1652-1660.

74. Seckl, J. R., Nyirenda, M. J., Walker, B. R., \& Chapman, K. E. (1999). Glucocorticoids and fetal programming. Biochemical Society Transactions, 27, 74-78.

75. Nepomnaschy, P. A., Welch, K. B., McConnell, D. S., Low, B. S., Strassmann, B. I., \& England, B. G. (2006). Cortisol levels and very early pregnancy loss in humans. Proceedings of the National Academy of Sciences of the United States of America, 103(10), 3938-3942. 
76. Arck, P., Hansen, P. J., Mulac Jericevic, B., Piccinni, M. P., \& Szekeres-Bartho, J. (2007). Progesterone during pregnancy: endocrine-immune cross talk in mammalian species and the role of stress. American journal of reproductive immunology, 58(3), 268-279.

77. Albrecht, E. D., Nightingale, M. S., \& Townsley, J. D. (1978). Stress-induced decreases in the serum concentration of progesterone in the pregnant baboon. Journal of Endocrinology, 77(3), 425-426.

78. Bateman, A. W., Coulson, T., \& Clutton-Brock, T. H. (2011). What do simple models reveal about the population dynamics of a cooperatively breeding species? Oikos, 120(5), 787-794.

79. Doolan, S. P., \& Macdonald, D. W. (1997). Breeding and juvenile survival among slendertailed meerkats (Suricata suricatta) in the south-western Kalahari: ecological and social influences. Journal of Zoology, 242(2), 309-327.

80. Russell, A. F., Brotherton, P. N. M., McIlrath, G. M., Sharpe, L. L., \& Clutton-Brock, T. H. (2003). Breeding success in cooperative meerkats: effects of helper number and maternal state. Behavioral Ecology, 14(4), 486-492.

81. Moss, A. M., Clutton-Brock, T. H., \& Monfort, S. L. (2001). Longitudinal gonadal steroid excretion in free-living male and female meerkats (Suricata suricatta). General and comparative endocrinology, 122(2), 158-171.

82. Sharp, S. P., English, S., \& Clutton-Brock, T. H. (2013). Maternal investment during pregnancy in wild meerkats. Evolutionary ecology, 27(5), 1033-1044.

83. delBarco-Trillo, J., Greene, L. K., Goncalves, I. B., Fenkes, M., Wisse, J. H., Drewe, J. A., Manser, M. B., ... \& Drea, C. M. (2016). Beyond aggression: Androgen-receptor blockade modulates social interaction in wild meerkats. Hormones and behavior, 78, 95-106. 
84. Brown, J., Walker, S. \& Steinman, K. (2004). Endocrine manual for the reproductive assessment of domestic and non-domestic species. Endocrine Research Laboratory, Department of Reproductive Sciences, Conservation and Research Center, National Zoological Park, Smithsonian Institution, Handbook, 1-93.

85. Starling, A. P., Charpentier, M. J., Fitzpatrick, C., Scordato, E. S., \& Drea, C. M. (2010). Seasonality, sociality, and reproduction: long-term stressors of ring-tailed lemurs (Lemur catta). Hormones and Behavior, 57(1), 76-85.

86. Wasser, S. K., Hunt, K. E., Brown, J. L., Cooper, K., Crockett, C. M., Bechert, U., ... \& Monfort, S. L. (2000). A generalized fecal glucocorticoid assay for use in a diverse array of nondomestic mammalian and avian species. General and comparative endocrinology, 120(3), 260-275.

87. Goncalves, I. B., Heistermann, M., Santema, P., Dantzer, B., Mausbach, J., Ganswindt, A., \& Manser, M. B. (2016). Validation of a fecal glucocorticoid assay to assess adrenocortical activity in meerkats using physiological and biological stimuli. PloS one, 11(4), e0153161.

88. Einarsson, S., Madej, A., \& Tsuma, V. (1996). The influence of stress on early pregnancy in the pig. Animal Reproduction Science, 42(1-4), 165-172.

89. Guo, Y., Hendrickx, A. G., Overstreet, J. W., Dieter, J., Stewart, D., Tarantal, A. F., ... \& Lasley, B. L. (1999). Endocrine biomarkers of early fetal loss in cynomolgus macaques (Macaca fascicularis) following exposure to dioxin. Biology of reproduction, 60(3), 707713.

90. Hanly, S. (1961). Prenatal mortality in farm animals. Journal of reproduction and fertility, 2(2), 182-194. 
91. Small, M. F. (1982). Reproductive failure in macaques. American Journal of Primatology, 2(2), 137-147.

92. Parker, V. J., \& Douglas, A. J. (2010). Stress in early pregnancy: maternal neuroendocrine-immune responses and effects. Journal of reproductive immunology, 85(1), 8692.

93. Clutton-Brock, T. H., Albon, S. D., \& Guinness, F. E. (1989). Fitness costs of gestation and lactation in wild mammals. Nature, 337(6204), 260-262.

94. Gittleman, J. L., \& Thompson, S. D. (1988). Energy allocation in mammalian reproduction. American zoologist, 28(3), 863-875.

95. Oftedal, O. T., \& Gittleman, J. L. (1989). Patterns of energy output during reproduction in carnivores. In Carnivore behavior, ecology, and evolution (pp. 355-378). Springer US.

96. Clutton-Brock, T., \& Sheldon, B. C. (2010). Individuals and populations: the role of longterm, individual-based studies of animals in ecology and evolutionary biology. Trends in Ecology \& Evolution, 25(10), 562-573.

97. Creel, S., Creel, N. M., Mills, M. G., \& Monfort, S. L. (1997). Rank and reproduction in cooperatively breeding African wild dogs: behavioral and endocrine correlates. Behavioral Ecology, 8(3), 298-306.

98. Licht, P., Frank, L. G., Pavgi, S., Yalcinkaya, T. M., Siiteri, P. K., \& Glickman, S. E. (1992). Hormonal correlates of 'masculinization' in female spotted hyaenas (Crocuta crocuta). 2. Maternal and fetal steroids. Journal of reproduction and fertility, 95(2), 463474. 
99. Drea, C. M. (2011). Endocrine correlates of pregnancy in the ring-tailed lemur (Lemur catta): implications for the masculinization of daughters. Hormones and behavior, 59(4), 417-427.

100. Fortman, J. D., Herring, J. M., Miller, J. B., Hess, D. L., Verhage, H. G., \& Fazleabas, A. T. (1993). Chorionic gonadotropin, estradiol, and progesterone levels in baboons (Papio anubis) during early pregnancy and spontaneous abortion. Biology of reproduction, 49(4), 737-742.

101. Hackländer, K., Möstl, E., \& Arnold, W. (2003). Reproductive suppression in female Alpine marmots, Marmota marmota. Animal Behaviour, 65(6), 1133-1140.

102. van Niekerk, C. H., \& Morgenthal, J. C. (1982). Fetal loss and the effect of stress on plasma progestagen levels in pregnant Thoroughbred mares. Journal of Reproduction and Fertility, 32, 453-457.

103. Creel, S., Creel, N., Wildt, D. E., \& Monfort, S. L. (1992). Behavioural and endocrine mechanisms of reproductive suppression in Serenge dwarf mongooses. Animal Behaviour, 43(2), 231-245.

104. Curtis, D. J., Zaramody, A., Green, D. I., \& Pickard, A. R. (2000). Non-invasive monitoring of reproductive status in wild mongoose lemurs (Eulemur mongoz). Reproduction, Fertility and Development, 12(2), 21-29.

105. Creel, S. R., Monfort, S. L., Wildt, D. E., \& Waser, P. M. (1991). Spontaneous lactation is an adaptive result of pseudopregnancy. Nature, 351(6328), 660.

106. Petty, J. M., \& Drea, C. M. (2015). Female rule in lemurs is ancestral and hormonally mediated. Scientific reports, 5, srep09631. 
107. Gesquiere, L. R., Khan, M., Shek, L., Wango, T. L., Wango, E. O., Alberts, S. C., \& Altmann, J. (2008). Coping with a challenging environment: effects of seasonal variability and reproductive status on glucocorticoid concentrations of female baboons (Papio cynocephalus). Hormones and behavior, 54(3), 410-416.

108. Pride, R. E. (2005). High faecal glucocorticoid levels predict mortality in ring-tailed lemurs (Lemur catta). Biology letters, 1(1), 60-63.

109. Scott, K., Heistermann, M., Cant, M. A., \& Vitikainen, E. I. (2017). Group size and visitor numbers predict faecal glucocorticoid concentrations in zoo meerkats. Open Science, 4(4), 161017.

110. Sapolsky, R. M. (1982). The endocrine stress-response and social status in the wild baboon. Hormones and behavior, 16(3), 279-292.

111. Young, A. J., \& Monfort, S. L. (2009). Stress and the costs of extra-territorial movement in a social carnivore. Biology Letters, rsbl-2009.

112. Young, A. J., Spong, G., \& Clutton-Brock, T. (2007). Subordinate male meerkats prospect for extra-group paternity: alternative reproductive tactics in a cooperative mammal. Proceedings of the Royal Society of London B: Biological Sciences, 274(1618), 1603-1609.

113. Smyth, K. N., Greene, L. K., Clutton-Brock, T., \& Drea, C. M. (2016). Androgens predict parasitism in female meerkats: a new perspective on a classic trade-off. Biology letters, 12(10), 20160660.

114. Wingfield, J. C., \& Romero, L. M. (2001). Adrenocortical responses to stress and their modulation in free-living vertebrates. Comprehensive Physiology. 
115. Clutton-Brock, T. H., Maccoll, A., Chadwick, P., Gaynor, D., Kansky, R., \& Skinner, J. D. (1999). Reproduction and survival of suricates (Suricata suricatta) in the southern Kalahari. African Journal of Ecology, 37(1), 69-80.

116. Root, T. L., Price, J. T., Hall, K. R., \& Schneider, S. H. (2003). Fingerprints of global warming on wild animals and plants. Nature, 421(6918), 57.

117. Hayes, L. D., \& Schradin, C. (2017). Long-term field studies of mammals: what the shortterm study cannot tell us. Journal of Mammalogy, 98(3), 600-602.

118. Smith, J. E., Lehmann, K. D., Montgomery, T. M., Strauss, E. D., \& Holekamp, K. E. (2017). Insights from long-term field studies of mammalian carnivores. Journal of Mammalogy, 98(3), 631-641. 